\title{
Decision-Making Aid Tool to Support Renovation of Buildings with Industrialised All-in-One Technology Solutions ${ }^{\dagger}$
}

\author{
Begoña Serrano Lanzarote $\left(\mathbb{D}\right.$, Cristina Isabel Jareño Escudero* ${ }^{(\mathbb{C}}$, Diego Sanz Almela and Joan Romero Clausell \\ Instituto Valenciano de la Edificación (IVE), 46022 Valencia, Spain; bserrano@five.es (B.S.L.); \\ dsanz@five.es (D.S.A.); jromero@five.es (J.R.C.) \\ * Correspondence: cjareno@five.es; Tel.: +34-960-131-131 \\ + Presented at the Sustainable Places 2021, Rome, Italy, 29 September-1 October 2021.
}

Citation: Serrano Lanzarote, B.; Jareño Escudero, C.I.; Sanz Almela,

D.; Romero Clausell, J.

Decision-Making Aid Tool to Support Renovation of Buildings with Industrialised All-in-One Technology Solutions. Environ. Sci. Proc. 2021, 11, 4. https://doi.org/10.3390/ environsciproc2021011004

Academic Editor: Leticia

Ortega Madrigal

Published: 23 November 2021

Publisher's Note: MDPI stays neutral with regard to jurisdictional claims in published maps and institutional affiliations.

Copyright: (c) 2021 by the authors. Licensee MDPI, Basel, Switzerland. This article is an open access article distributed under the terms and conditions of the Creative Commons Attribution (CC BY) license (https:/ / creativecommons.org/licenses/by/ $4.0 /)$.

\begin{abstract}
Unlike other interventions for the improvement of energy efficiency, in the case of the application of prefabricated elements in deep renovations, there is a certain lack of knowledge on the part of potential clients or even technical staff. This article arises from this need, and its objective and main result is the development and presentation of a tool to help in making decisions on whether the industrialized building envelope kits in general and those of the H2020 INFINITE project are applicable in each specific case.
\end{abstract}

Keywords: renovation; energy performance; renewable energy technologies; circular economy; business models; BIM; digitalization; energy modeling

\section{Introduction}

The adoption of energy-efficient retrofit measures (EERMs) in residential buildings is critical to support the development of national and pan-European policies aimed at fostering the energy performance upgrade of the building stock [1].

Buildings are the key factor to transforming cities and contributing to recent European energy efficiency objectives for 2030 and 2050. New buildings account for only 1-2\% annually [2].

Industrialized all-in-one building envelope kits for deep renovation are competitive, reliable, and life-cycle-based. To be stakeholder-accepted and follow a sustainable approach contributing to decarbonization of the EU building stock, a decision-making aid tool has been conceived in the framework of INFINITE Horizon 2020 project.

INFINITE relies on an approach that combines digitalization and industrialisation to offer high-quality, tailor-made, sustainable solutions designed to last, named "Renovation $4.0^{\prime \prime}$.

INFINITE aims to develop five all-in-one industrialised envelope kits, designed to cover near ZEB retrofit needs. The range of technologies available includes passive ecocompatible and green envelope solutions, energy and fresh air distribution systems, smart windows (smart glazing), building integrated photovoltaic systems (BIPV) and solarthermal generation systems (BIST).

The design of the kits is made easy by a multi-user BIM platform with a palette of plugins dedicated to LCA/LCC, energy and comfort, and O\&M.

To cover the wide parameter variability on technical and implementing conditions, a segregation tool has been aimed to cover the variation in the building stock and identify limiting parameters. This process allowed us to understand which buildings typologies fit better with the industrialised approach and favour the penetration of industrialization in the market. 


\section{Methodology}

So far, analysis of the building stock has been done mainly from the point of view of energy efficiency, but industrialization can address more than one concept at a time.

EERMs that were identified as the top ten highest ranked were mostly related to the building envelope (i.e., Maintenance_Wall, Maintenance_Envelope + New _EnergyGeneration, Upgrade_Wall, Maintenance_Roof, Maintenance_Envelope + Upgrade_EnergyGeneration, New element_EnergyGeneration, New element_EnergyStorage, Upgrade_Roof, Upgrade_Envelope + New _EnergyGeneration, and New element_Ventilation). This finding can be attributed to the idea that actions to the building envelope addresses another relevant concern to building and dwelling owners, which is the aspect or appearance of the building and not necessarily cost-effective EE actions [1].

It is important to identify the factors affecting this new process to map and view future markets and needs from the supply and demand point of view. It is crucial to go further in the characterization of the building stock.

To identify the specific needs for the industrialised envelope kits, the previous experiences at a European level in the characterization of the residential building stock were studied. It is considered necessary in the first place to scan: TABULA [3], FP7 Inspire [4], H2020 4RinEU [5], H2020 MORE-CONNECT [3] and PLURAL.

\subsection{Decision-Making Aid Tool Development}

Once the previous experiences are scanned, the development of this decision-making aid tool is considered a viable solution to the need for decision support in the renovation of the building stock, in which some variability is observed, leading to uncertainty in the definition of the envelope solutions.

The tool, to be called the "Decision Tree Tool", is primarily intended to be able to tell anyone answering a few questions whether INFINITE prefabricated kits/solutions are applicable to their building or dwelling and secondarily to help the digital transformation of the construction industry, increasing its efficiency and improving its quality [6].

The methodology followed for the elaboration of the tool was structured in three phases:

1. Identification of the characteristics of buildings that affect the design and installation of industrialised elements.

2. Definition and classification of the building stock features to be considered.

3. Development of the decision-making aid tool.

\subsection{Identification of the Characteristics of Buildings That Affect the Design and Installation of Industrialized Elements}

The first step was the identification of the building characteristics affecting the feasibility of the use of an industrialised approach in the building renovation was carried out using the Delphi method [7], a forecasting process framework based on the results of multiple rounds of questionnaires sent to a panel of experts.

The panel of experts was constituted of those partners who participate in the design or exploitation of any of the products involved in the INFINITE framework, as they were considered representative of the different industrialized solutions applicable to the field of building renovation.

Partners were offered a list of the building parameters and they must order them considering their opinion on which affected the design of the industrialised envelope kits.

In this case, two rounds of questionnaires were sent out to the group of experts, and the anonymous responses were aggregated and shared with the group after each of the two rounds. The experts were allowed to adjust their answers, based on the "group response".

\subsection{Definition and Classification of the Building Stock Features to Be Considered}

Based on the results of the Delphi method, the characteristics selected by the panel of experts were classified in the order of importance given by the panel of experts. 
Based on the results obtained, two strategies were designed to present the data obtained in a useful way.

On the one hand, it was concluded that the representation of said information on a map using GIS technology would be more adequate allowing the incorporation of the data at different scales. The development of an interactive market potential map where the demand and the offer would be connected. In this regard, each of the characteristics identified was analyzed to figure out if it would be possible to obtain such data at the European or national level from dynamic and official sources to make incorporating such information in a GIS map feasible.

On the other hand, and this being the issue at stake here, given that the information collected included those characteristics of the buildings and their surroundings that influence industrialized renovation systems, it was proposed to develop a decision-making aid tool aimed at future clients that consists of an itinerary of questions that leads to an orientation regarding the type of system that is most suitable for each client.

\subsection{Development of the Decision-Making Aid Tool}

The development of a decision-making tool was proposed as a useful result to help the demand side (users and designers) to figure out if industrialized solutions are feasible for their specific situation. The steps followed to make the tool were:

- Analysis of the parameters listed in the two previous rounds of the Delphi method and elaboration of a set of questions to obtain the key information.

- Preparation of specific technical questionnaires for each technical solution, selecting the key questions based on the conclusions of the Delphi method.

- Specific technical questionnaires per solution and adjusted to the features of each technical system were proposed among the industrial partners/technical providers to identify the feasibility of their solutions based on the different parameters studied previously, to find out under what circumstances their solution would not be viable.

Once the answers to the technical questionnaires were collected, then a process of analysis of the answers to better understand each of the kits and identification of the limiting parameters that prevent the viability of the system was run to help the development of the draft of the tool. After that, the draft was sent to partners for supervision.

\section{Results}

After all the processes detailed above, a series of results are extracted from each of the previous steps.

\subsection{Delphi Method}

Due to the type of characteristics highlighted by the experts, as well as to the dispersion in relation to the importance of each parameter among the different products studied, it was concluded that was impossible to represent the information in a matrix format, as the matrix was the format thought of as the best one before carrying out the analysis.

\subsection{Technical Questionnaires}

As a result of the questionnaires proposed among the technical partners, it was possible to refine the really limiting criteria of each system or kit, since despite being questionnaires based on the group results of the Delphi method, the content was technically adapted to each of the systems individually. That is to say, in the kits in which some of the characteristics were not relevant, for example, the incidence of the sun, questions related to this aspect were not included, so the answers were more specific or natural to the kit to be developed.

\subsection{Decision-Making Aid Tool}

The current result of the tool is a programmed spreadsheet that can indicate to anyone who answers a set of questions if the different solutions are applicable to their specific 
building/dwelling and to find out under what circumstances their solution would not be viable.

This tool is intended for end users (owners, investors, designers...), hence the type and specification of the questions and a language that is as simple and understandable as possible.

The way to use the tool is to answer the questions strictly following the order proposed (from the top to the bottom), as depending on the choice, some of the questions disappear. So, after answering all the questions that come up, the possible kits to be installed are shown. An extract of the questions and answers is shown in Table 1.

Table 1. Extract of the programmed spreadsheet.

\begin{tabular}{|c|c|}
\hline $\begin{array}{l}\text { Questions to Be Asked to the Users (e.g.,: } \\
\text { Final Users) }\end{array}$ & Answers \\
\hline $\begin{array}{l}\text { Is it residential use or another type of use: } \\
\text { commercial, administrative, educational ... ? }\end{array}$ & Residential \\
\hline What type of user are you? & Owner/representative of a building \\
\hline $\begin{array}{l}\text { Does the building have any kind of } \\
\text { patrimonial/cultural protection? }\end{array}$ & Yes \\
\hline $\begin{array}{l}\text { Does the sun affect your façade during the day? } \\
\text { (e.g.,: rays of sun enter through the windows) }\end{array}$ & Yes \\
\hline $\begin{array}{l}\text { Are there restrictions on the use of water in } \\
\text { your area? (e.g.,: limited use of liters per day) }\end{array}$ & No \\
\hline
\end{tabular}

Since this work is part of an ongoing research project, the final image of the tool will be presented after a future web development process to make it user-friendly and modular to add other supporting functionalities that may arise during the development of the European INFINITE project.

\section{Conclusions}

Since the final objective was to favour the penetration of industrialization in the market, after the study and analysis of the previous parameters for the realization of the tool, and its subsequent development and digitalisation following the exposed methodology, several things can be concluded:

- The application of prefabricated systems in the renovation of existing buildings, as opposed to new buildings or other types of energy efficient renovations, depends on a wide range of parameters.

- This wide variability of features presents great difficulty in reproducing a functional closed matrix.

- The local regulations applicable in each country make it difficult to homogenize selection and decision-making patterns.

- The product range, according to the use of the tool, could grow and specialize depending on the area and demand. To this end, the tool will be adapted and made more flexible to accommodate the largest number of prefabricated systems.

Therefore, with this decision-making aid tool, a standardized protocol can be proposed that overcomes the uncertainty generated by the interregional scenario of the population consulted, minimizing the deviation of the results obtained and homogenizing a questionanswer relationship (QAR) structure of the sources consulted.

As part of ongoing research, the next steps to follow will be to develop a GIS map crossing demand and offer drawn up with the available data. This would identify where the demand for such systems is highest and identify potential markets where they could be implemented faster. This also encourages their development and continuous improvement. 
Future research could focus on the definition of different building archetypes that also help the demand side (users and designers) to figure out if the industrialized all-in-one building envelope kits are feasible for their specific dwelling or building.

Data Availability Statement: Data available in a publicly accessible repository that does not issue DOIs. Publicly available datasets were analyzed in this study. This data can be found here: https: / / webtool.building-typology.eu/\#bm (accessed on 8 October 2021); https: / / inspire-fp7.eu/ retrofitsolutions-database/building-stock-statistics / (accessed on 8 October 2021); https://www.moreconnect.eu/wp-content/uploads/2019/07/MORE-CONNECT_WP2_D2.1-Initil-performance-criteria. pdf (accessed on 8 October 2021); https: / / 4rineu.eu/reports / (accessed on 8 October 2021).

Conflicts of Interest: The authors declare no conflict of interest.

\section{References}

1. Camarasa, C.; Kalahasthi, L.K.; Sanchez-Díaz, I.; Rosado, L.; Hennes, L.; Bienge, K.; Hamilton, I. Energy-Efficient Retrofit Measures (EERM) in Residential Buildings: An Application of Discrete Choice Modelling. Buildings 2021, 11, 257. [CrossRef]

2. Vavallo, M.; Arnesano, M.; Revel, G.M.; Mediavilla, A.; Sistiaga, A.F.; Pracucci, A.; Magnani, S.; Casadei, O. Accelerating Energy Renovation Solution for Zero Energy Buildings and Neighbourhoods-The Experience of the RenoZEB Project. Proceedings 2019, 20, 1. [CrossRef]

3. van Oorschot, J.A.W.H. Housing typology Assessment MORE-CONNECT WP3.1. European Report: Vol. Version 7. 2016. Available online: https:/ / www.more-connect.eu/wp-content/uploads/2018/04/HOUSING-TYPOLOGY-3.1.pdf (accessed on 8 October 2021).

4. Fedrizzi, R. PROJECT FINAL REPORT Grant Agreement Number: 314461. Project Acronym: INSPIRE. Project Title: Development of Systemic Packages for Deep Energy Renovation of Residential and Tertiary Buildings Including Envelope and Systems. 2016. Available online: http:/ /inspire-fp7.eu (accessed on 8 October 2021).

5. Pernetti, R.; Pinotti, R.; Lollini, R.; Paoletti, G.; Toledo, L. Renovation Packages—4RinEU Project I Renovation of Residential buildings in EU. 2020. Available online: https:/ / 4rineu.eu/2018/11/14/renovation-packages/ (accessed on 8 October 2021).

6. Elagiry, M.; Dugue, A.; Costa, A.; Decorme, R. Digitalization Tools for Energy-Efficient Renovations. Proceedings 2020, 65, 9. [CrossRef]

7. Dalkey, N.; Helmer, O. An experimental application of the Delphi method to the use of experts. Manag. Sci. 1963, 9, 458-467. [CrossRef] 